\title{
Formation of Conidial Pseudochains by Tomato Powdery Mildew Oidium neolycopersici
}

\author{
W. Oichi, Y. Matsuda, T. Nonomura, and H. Toyoda, Laboratory of Plant Protection and Biotechnology, Faculty of \\ Agriculture, Kinki University, 3327-204 Nakamachi, Nara 631-8505, Japan; L. Xu, School of Life Science, East \\ China Normal University, Shanghai 200062, China; and S. Kusakari, Agricultural, Food and Environmental Sci- \\ ences Research Center of Osaka Prefecture, Osaka, 583-0862, Japan
}

\begin{abstract}
Oichi, W., Matsuda, Y., Nonomura, T., Toyoda, H., Xu, L., and Kusakari, S. 2006. Formation of conidial pseudochains by tomato powdery mildew Oidium neolycopersici. Plant Dis. 90:915919 .

The formation of conidial pseudochains by the tomato powdery mildew Oidium neolycopersici on tomato leaves was monitored using a high-fidelity digital microscope. Individual living conidiophores that formed mature conidial cells at their apex were selected for observation. The conidial cells were produced during repeated division and elongation by the generative cells of the conidiophores. Under weak wind conditions $(0.1 \mathrm{~m} / \mathrm{s})$, these conidial cells did not separate from each other to produce a chain of conidial cells (pseudochain). The pseudochains dropped from the conidiophores once four conidial cells were connected. The conidiophores resumed conidium production, followed by another cycle of pseudochain formation. The formation of pseudochains by tomato powdery mildew was not influenced by the ambient relative humidity. On the other hand, the conidial cells produced were easily wind dispersed without forming pseudochains when conidiophores were exposed to stronger winds $(1.0 \mathrm{~m} / \mathrm{s})$. The present study successfully demonstrated that the pathogen required wind to disperse progeny conidia from the conidiophores and produced conidial pseudochains when the wind was below a critical level, independent of high relative humidity as reported previously.
\end{abstract}

Starting in 1998, annual outbreaks of powdery mildew have been detected in the commercial tomato cultivars grown in greenhouses of Kinki University (Nara Prefecture, Japan). This disease is especially severe in young seedlings, and has expanded vigorously to the field when chemical control was insufficient. Our previous work (13) revealed that commercial tomato cultivars available in Japan were highly susceptible to natural infection by powdery mildew. A similar severe disease outbreak had occurred in greenhouse and field-grown tomato in several European countries $(4,10,17,18,20,23,24)$, Canada (3), and the United States $(1,8,12,21,22,25)$. However, no article has described the formation of cleistothecia by these powdery mildews. Kiss et al. (11) reported that all recent outbreaks of tomato powdery mildew outside Australia were caused by a species that formed conidia singly or, occasionally, in pseudochains of two to six conidia in high relative humidity, and proposed the creation of a new species, Oidium neolycopersici, provided

Corresponding author: H. Toyoda

E-mail: toyoda@nara.kindai.ac.jp

Accepted for publication 27 February 2006.

DOI: 10.1094/PD-90-0915

(C) 2006 The American Phytopathological Society that the Australian isolates that always formed conidia in chains retained the name O. lycopersici. According to their criteria, a Japanese isolate of the tomato powdery mildew was identified as $O$. neolycopersici L. Kiss (KTP-01) (9).

With an expansion of the disease in many tomato cultivation areas of Japan, rapid detection of the causal pathogen has become a major concern. Because differentiation of the new, aggressive species is based in part on the conidiogenesis of tomato powdery mildew fungi, conidial formation is likely to be an important and reliable characteristic for preliminary identification of the pathogen. According to Kiss et al. (11), the conidiophores of $O$. neolycopersici frequently produce single conidia in low relative humidity and conidial pseudochains in high humidity. Nevertheless, Japanese field workers recognized that the pathogen produces conidial pseudochains under dry field conditions. This apparent contradiction caused confusion among field workers, who assumed the occurrence of a new type of the tomato powdery mildew that forms conidia in chains under conditions of low humidity. Thus, it became an urgent matter to accurately assess the formation of the conidial pseudochains by the tomato powdery mildew under realistic conditions of relative humidity. In the present study, we clarify pseudochain formation by in situ observation of living conidiophores on tomato leaves with a high-fidelity digital microscope, and describe a possible mechanism for the formation of conidial pseudochains by an isolate (KTP-01) of O. neolycopersici.

\section{MATERIALS AND METHODS}

Pathogen and plants. The conidia of $O$. neolycopersici KTP-01, which were isolated from naturally infected tomato leaves (9), were used for this study. Seedlings of tomato (Lycopersicon esculentum Mill, cv. Moneymaker) were susceptible to KTP-01 (14). Germinated seed of Moneymaker were sowed in vermiculite in a tray, and 10-day-old seedlings were transplanted to autoclaved soil in $15-\mathrm{cm}$ pots. The plants were grown in the propagation greenhouse for 20 days, then transferred to the inoculation greenhouse $\left(25 \pm 3^{\circ} \mathrm{C}\right.$; diurnal change of relative humidity $[\mathrm{RH}], 45$ to $90 \%$; intermittent wind by ventilation, 0.1 to 1.0 $\mathrm{m} / \mathrm{s}$ ). The conidia of KTP-01 were dusted onto all leaves of 1-month-old seedlings with a brush, and newly produced conidia of 6-day-old colonies were used for the subsequent inoculation.

Effect of RH on the formation of conidial pseudochains. Inoculated tomato plants were transferred to growth chambers $\left(25 \pm 1^{\circ} \mathrm{C}\right.$, continuous wind of $\left.0.1 \mathrm{~m} / \mathrm{s}\right)$ automatically regulated at different RHs of (i) 20 to 35 , (ii) 50 to 60 , (iii) 65 to 80 , and (iv) 95 to $100 \%$. The colony-forming leaves of inoculated plants were observed directly using an objective zoom lens MX2525CS $(\times 1,000)$ of a high-fidelity digital microscope KH-2700 (Hirox, Tokyo) according to the method described previously (19). In each experiment, 10 colonies on five plants were selected at random to count the number of conidiophores with single conidia or with conidial pseudochains. More than 1,500 conidiophores per colony were observed. The data were given as the means of three replications.

Digital microscopic observation of conidial pseudochain formation. Inoculated plants were placed in an incubation cabinet at $25 \pm 3^{\circ} \mathrm{C}, 20$ to $35 \% \mathrm{RH}$, with continuous illumination of 3,000 lux with fluorescent lamps, and intermittent wind of 0.1 $\mathrm{m} / \mathrm{s}$. At 5 days after inoculation, immature conidiophores were selected and continuously observed using the high-fidelity digital microscope. Digitized images of the conidiophores were obtained at 15-min 


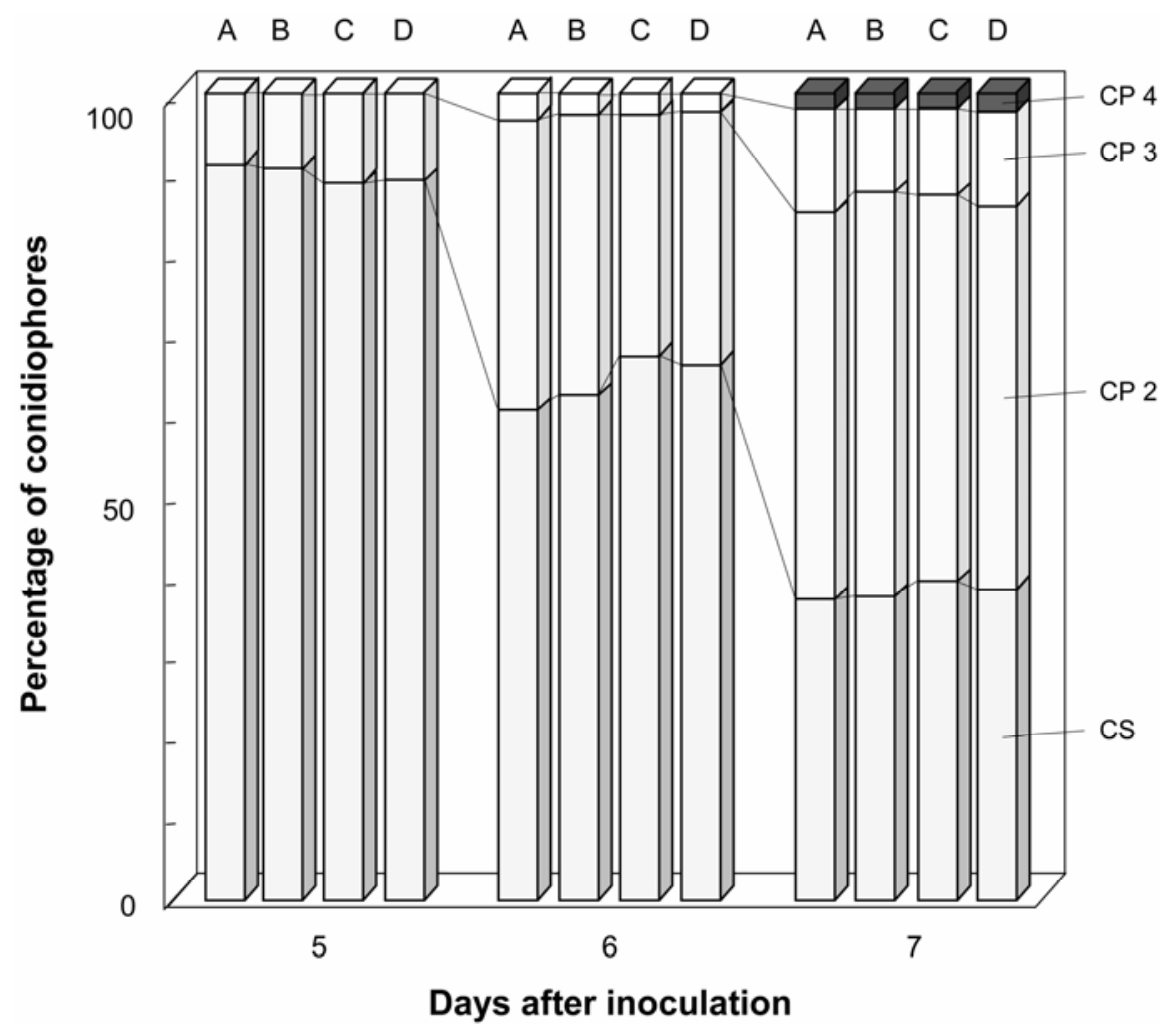

Fig. 1. Percentage of conidiophores forming conidia singly (CS) or in pseudochains (CP) in the colonies of Oidium neolycopersici KTP-01 on the leaves of tomato plants grown under different relative humidities. A-D, Relative humidity of 20 to 35,50 to 60,65 to 80 , and 95 to $100 \%$, respectively. CP 2 , 3 , and 4 represent pseudochains with two, three, and four conidial cells, respectively. In all, 1,500 conidiophores were observed from 10 colonies on each of 5 tomato plants, and data are expressed as the means of five separate experiments.

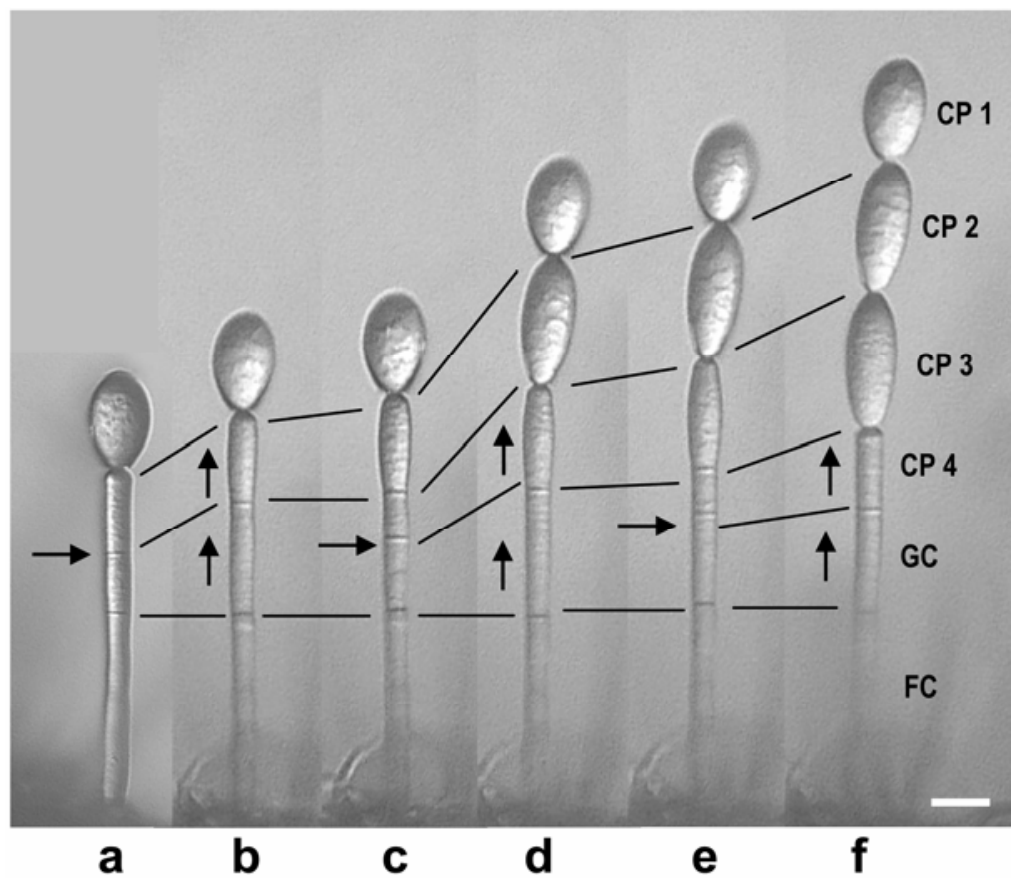

Fig. 2. Digital micrographs of conidial pseudochains formed by Oidium neolycopersici KTP-01 on tomato leaves. The micrographic series (a to f) illustrates the consecutive developmental changes of the same conidiophore under low relative humidity (20 to 35\%) and wind $(0.1 \mathrm{~m} / \mathrm{s})$ conditions. Perpendicular and horizontal arrows represent the stage of growth and septation of a generative cell, respectively. Abbreviations: FC, foot cell; GC, generative cell; CP 1 to 4 , first to fourth cell in the pseudochain, respectively. Bar $=10 \mu \mathrm{m}$. intervals at an isofocal point with a $1 / 2$ ' Interline Transfer CCD (charge-coupled device) camera and Adobe Photoshop software (version 5.0; Adobe, San Jose, CA).

The observation of conidiophores also was conducted under the same conditions but with stronger wind conditions (1.0 $\mathrm{m} / \mathrm{s}$ ) as measured at the site of the plants using an anemometer testo-425 (Testoterm, Lenzkirch, Germany). More than 50 conidiophores were used for each experiment. Additionally, the observation was carried out after the inoculated leaves were incubated for 7 days under weak wind conditions and then subjected to the stronger wind to examine the release of conidial cells from the pseudochains. The conidia released were trapped with a glass plate $\left(30\right.$ by $30 \mathrm{~cm}^{2}$ ) placed horizontally $30 \mathrm{~cm}$ from the leaves for microscopic observation.

Micromanipulation of conidia from pseudochains for germination assay. Using a micromanipulator (Narishige Co., Ltd., Tokyo, Japan), pseudochain conidia were transferred individually onto a cellulose membrane on solidified agar 5 to 7 days after inoculation to check their germination. Conidia were placed in the growth chamber $\left(25 \pm 0.5^{\circ} \mathrm{C}\right)$, incubated for $10 \mathrm{~h}$, and observed according to the method described previously (15).

Greenhouse and field assays. Inoculated tomato plants were grown in the greenhouse under weak $(0.1 \mathrm{~m} / \mathrm{s})$ or stronger $(1.0 \mathrm{~m} / \mathrm{s})$ wind conditions produced by an electric fan. Leaves of the inoculated plants with colonies were harvested 10 days after inoculation and observed with the digital microscope. Conidiophores on the leaves of field-grown tomato plants naturally infected with tomato powdery mildew were collected and observed with the digital microscope. In all, 100 colonies from 85 leaves of 50 plants were selected at random to determine whether the colonies formed the conidia singly or in chains at the conidiophore apex, for all treatments. Observations were conducted on a day following 5 days of continuously calm weather (less than $0.1 \mathrm{~m} / \mathrm{s}$ ) or on the day after $4 \mathrm{~h}$ of a stronger morning wind ( 1.0 to $2.8 \mathrm{~m} / \mathrm{s}$ ).

In addition, the colonies with pseudochain on the field-grown plants were blown $(1.0 \mathrm{~m} / \mathrm{s})$ for $1 \mathrm{~h}$ with an electric fan. The conidia were trapped and examined as above.

\section{RESULTS}

We examined the relationship between $\mathrm{RH}$ and pseudochain formation by the tomato powdery mildew. The percentage of conidiophores forming conidia singly or in pseudochains in 5-, 6-, and 7-day-old colonies under different $\mathrm{RH}$ conditions is shown in Figure 1. The number of the conidiophores with conidial pseudochains increased with colony age. However, the 
percentages did not vary significantly among RH conditions. The number of the conidial cells in the pseudochains did not exceed four throughout the course of observation.

Observation of pseudochain formation on the leaves of inoculated plants grown under the lowest humidity conditions (20 to $35 \% \mathrm{RH})$ and weak wind $(0.1 \mathrm{~m} / \mathrm{s})$ showed that mature conidial cells initially appear at the conidiophore apex 5 days after inoculation. We monitored individual conidiophores for pseudochain formation using the digital microscope. Consecutive digital micrographs focusing on a single living conidiophore on a host leaf are shown in Figure 2, and Figure 3A diagrammatically represents conidial pseudochain formation through the repeated elongation and septation-mediated cell division by generative cells. After maturation of the first conidial cells, the second conidial cells of the conidiophores matured without abstricting the first conidial cells, concurrently with the elongation and division by the generative cells (Figs. 2 and 3A, a to d). The generative cells again elongated and divided into two cells by septation to produce third conidial cells ( $\mathrm{d}$ to $\mathrm{f}$ ) and, similarly, fourth conidial cells (Fig. 3A, f to $h)$. At this stage, the pseudochains with four conidial cells separated from the conidiophores (Fig. 3A, h and i). After the release of the pseudochain, the conidiophores resumed conidium production (Fig. $3 \mathrm{~A}, \mathrm{i}$ and $\mathrm{j}$ ), followed by the same cycle of pseudochain formation. During the tracking of the living conidiophores (450 colonies on 135 leaves of 60 plants), we confirmed that pseudochains never exceeded five conidial cells in the colonies observed and that, in all conidiophores observed, the cycle of pseudochain formation was limited to four or five times.

Individual conidial cells in the pseudochains were separated easily during micromanipulation (Fig. 4). These conidia were transferred to an artificial membrane to examine their germination. Nearly all $(98.6 \%)$ of the transferred conidia germinated normally, indicating that each conidial cell in the pseudochain was developmentally competent.

Repeated pseudochain formation was observed only under weak wind conditions during the period of conidium formation. Under stronger wind conditions $(1.0 \mathrm{~m} / \mathrm{s})$, conidial cells were produced in the same manner of elongation and division by generative cells, but were dispersed easily from the apex of the conidiophores without forming pseudochains (Fig. 3B). As a result of this wind dispersal of the conidia, all of the observed conidiophores (530 conidiophores) either were conidium-free or formed only single conidia.

Conidial cells formed in pseudochains were separated by the stronger wind conditions after the pseudochains were formed. All of the 1,280 conidia from 16 colonies collected on the glass plates were found to be single.

We examined whether the controlled laboratory conditions could be extrapolated to pseudochain formation by the pathogen infecting plants in the greenhouse. Under weak wind conditions, $15 \%$ of conidiophores had no conidia, $20 \%$ had single conidia, and $65 \%$ were observed with pseudochains of two to four cells (2,400 conidiophores from 40 colonies of 10 inoculated plants). The different types of the conidiophores in a 7-day-old colony are shown in Figure 5A. Moreover, abundant fallen conidial pseudochains were observed at the base of the conidiophores. On the other hand, only two types of the conidia (without conidia or with single conidia) were detected in 1,600 colonies of 10 plants under the stronger wind conditions (Fig. 5B). These results were in agreement with the laboratory data.

The conidiophores on the leaves of field-grown tomato plants were observed using the digital microscope. After the stronger wind, all of the colonies $(n=100)$ tested had either naked conidiophores or a single conidium. On the other hand, 98 of the 100 tested colonies formed pseudochains with two to four conidial cells at the conidiophore apex during 5 days of calm whether. No conidiophore formed more than a total of five conidial cells in the colonies from naturally infected tomato plants.

In the colonies from naturally infected tomato plants, numerous conidial pseudochains were found at the base of the conidiophores in addition to the apex. These conidial pseudochains were driven from the colonies by the electric fan. In this experiment, 11,996 conidia from 40 colonies were collected on the glass plate; all were in single form. The germination rate of the collected conidia was $72.5 \pm 11.1 \%$.

\section{DISCUSSION}

Powdery mildew that causes severe damage on greenhouse tomato has been
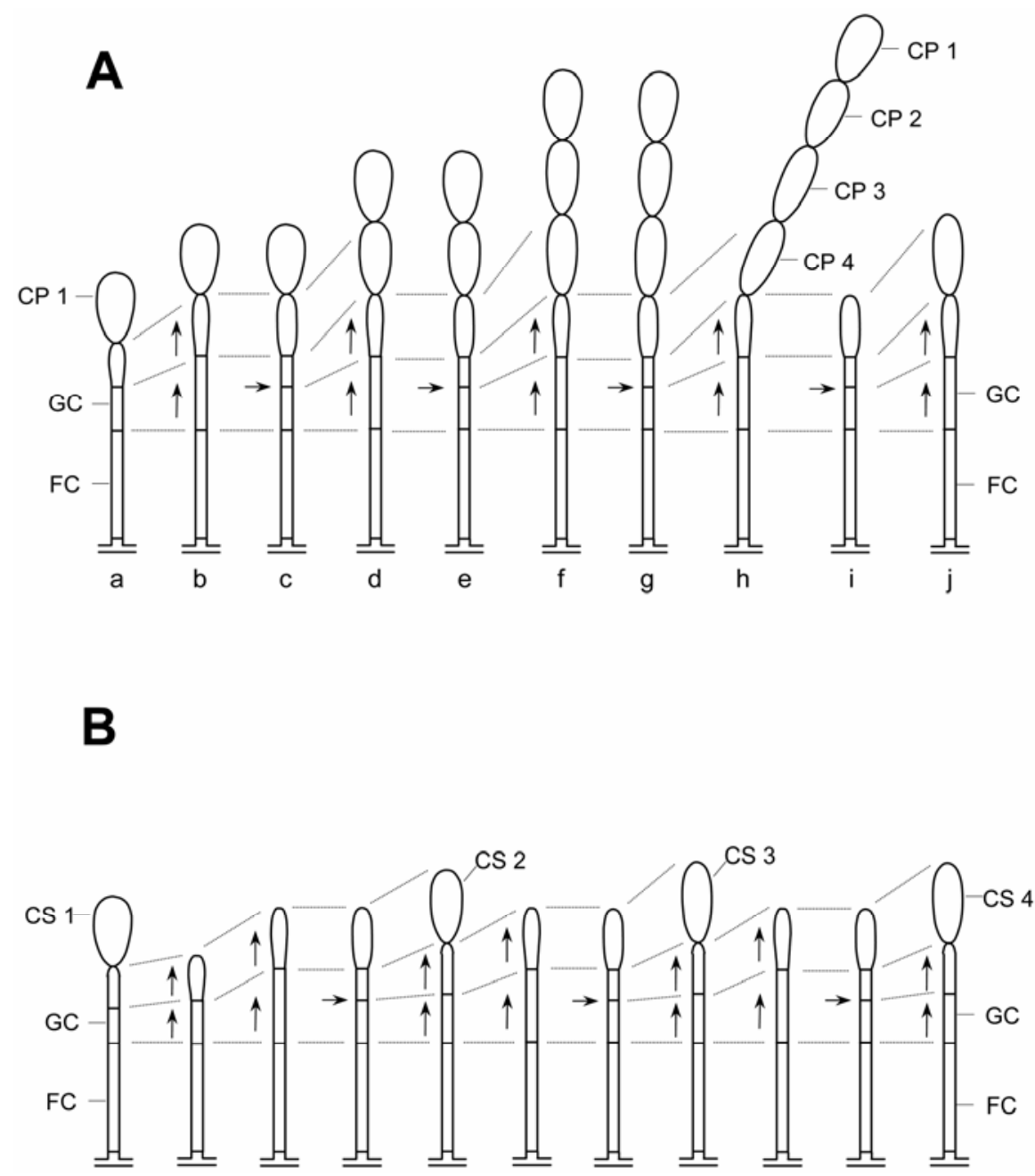

Fig. 3. Diagram of the developmental process of conidiogenesis by a conidiophore of Oidium neolycopersici KTP-01 on a tomato leaf. A, Formation of a pseudochain with four conidial cells under low relative humidity (20 to $35 \%)$ and wind $(0.1 \mathrm{~m} / \mathrm{s})$ conditions. B, Repeated conidium formation and secession under stronger wind $(1.0 \mathrm{~m} / \mathrm{s})$ conditions. Perpendicular and horizontal arrows represent the stage of growth and septation of a generative cell, respectively. Abbreviations: FC, foot cell; GC, generative cell; CP 1 to 4 , first to fourth cell in the pseudochain, respectively; CS 1 to 4, first to fourth conidial cells formed after the abstriction of each conidium. 
reported worldwide. Powdery mildew pathogens produced fibrosin body-free conidia singly $(6,7,11,12,18,20,22,24)$, in short chains $(1,10,17,21,25)$, or both $(3,5,8,23)$. Kiss et al. defined the formation of a series of conidial cells (pseudochain) as a characteristic of $O$. neolycopersici, especially in high humidity, and distinguished these pseudochain-forming pathogens from the powdery mildews-forming catenated conidia (11). The observation of differences in conidial formation provided a simple method for discriminating between powdery mildew types, but the mechanisms of conidial pseudochain formation by this pathogen have remained obscure.
Our aim in the present study was to clarify how tomato powdery mildew produces conidial pseudochains on host leaves. To accurately analyze this process, we selected a microscopic technique to minimize artificial release of the conidia from the conidiophores during sample preparation. The high-fidelity digital microscope was a suitable tool for this purpose, and enabled the observation of living pathogens in situ with high resolution without chemical treatments for leaf clearance and fungal staining (15). With this microscopic technique, we were able to continuously monitor conidium formation on living conidiophores $(16,19)$. We also exploited this technique to analyze the developmen-
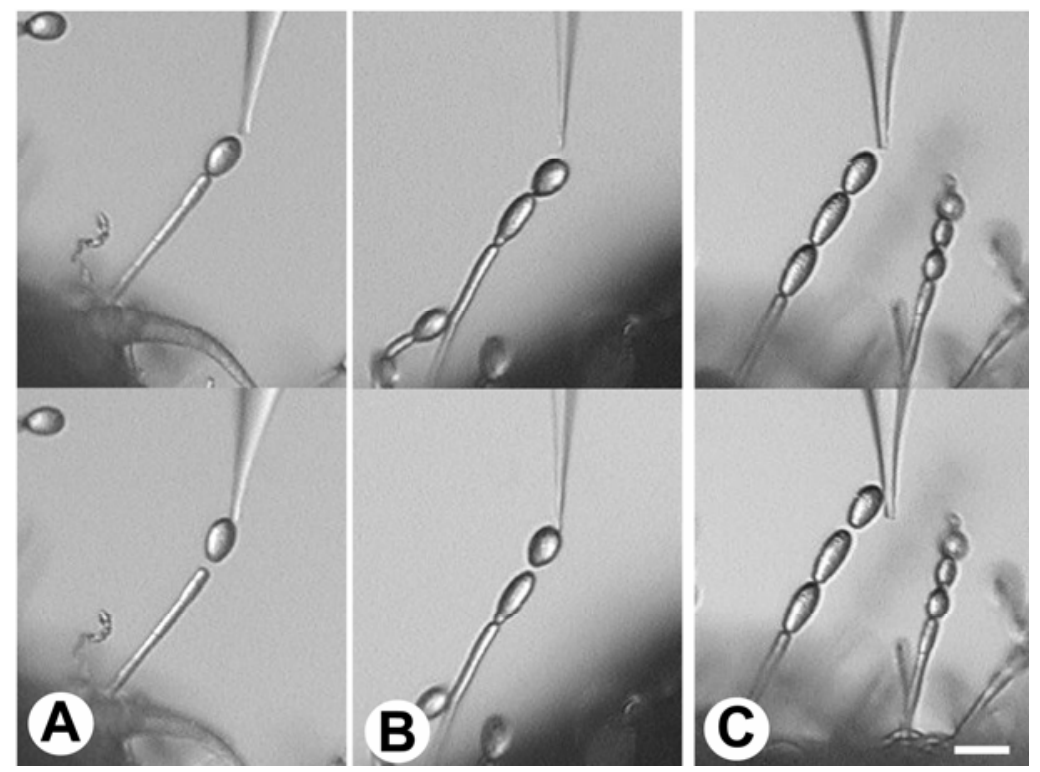

Fig. 4. Successful separation of conidial cells from the pseudochains of Oidium neolycopersici KTP01 on tomato leaves with a micromanipulator. Conidia formed $\mathbf{A}$, singly or $\mathbf{B}$ and $\mathbf{C}$, in pseudochains on conidiophores were separated and transferred to a membrane to examine germination. Bar $=20 \mu \mathrm{m}$.
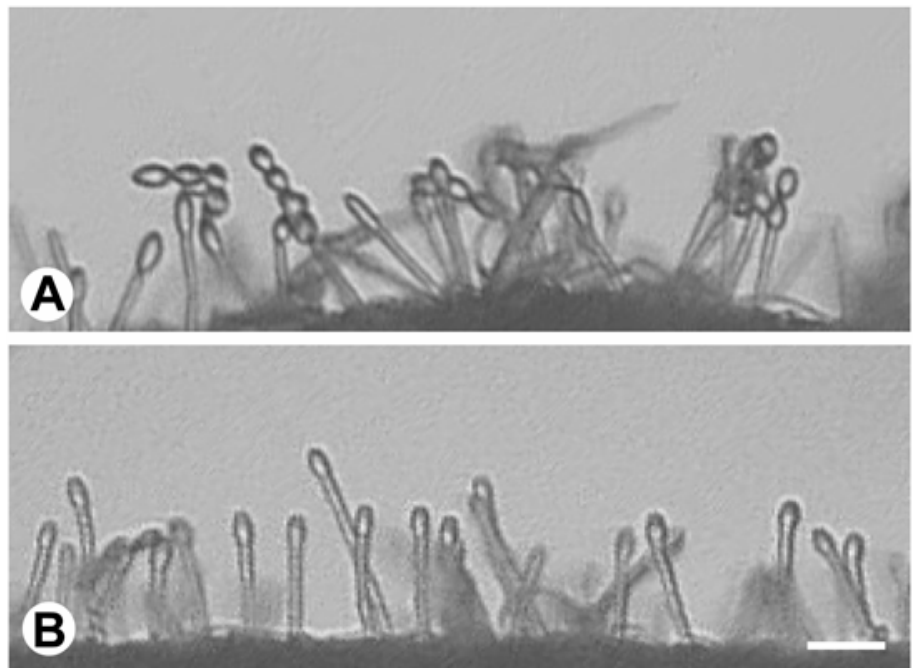

Fig. 5. Conidiophores in 7-day-old colonies of Oidium neolycopersici KTP-01 on leaves of inoculated tomato plants grown in the greenhouse under different wind conditions. Inoculated plants were kept under A, continuously weak $(0.1 \mathrm{~m} / \mathrm{s})$ or $\mathbf{B}$, stronger $(1.0 \mathrm{~m} / \mathrm{s})$ wind conditions provided by an electric fan. Note different types of conidiophores forming conidia singly or in pseudochains with two to four cells in weak wind (A), compared with the conidiophores with single conidia or without mature conidia in stronger wind $(\mathrm{B})$. $\mathrm{Bar}=40 \mu \mathrm{m}$.

tal process for conidial pseudochain formation by $O$. neolycopersici.

In our previous work (19), we clarified the entire process of conidiogenesis by the tomato powdery mildew fungus. This process involved the development of generative cells and their division by the repeated septation of the conidiophore to produce the initial mature conidia at the conidiophore apex. The present work successfully followed this process and demonstrated how the pathogen forms conidial pseudochains. The generative cells of the conidiophores successively developed conidial cells in the same manner as one reported previously (19); however, these conidial cells were not released from each other under weak wind conditions, which may be considered a primary criterion for the definition of conidial pseudochains. Some workers have described the involvement of high $\mathrm{RH}$ in the pseudochain formation by tomato powdery mildew (11). However, the present study indicated that pseudochain formation by KTP-01 was not influenced by RH.

The pseudochains of KTP-01 apparently detach from conidiophores by their own weight when four mature conidial cells are connected, and then the conidiophores resume the cycle of pseudochain formation. So far as we observed the KTP-01 colonies, no conidiophores formed pseudochains with more than five conidial cells. On the other hand, some investigators reported different numbers, such as two to six conidial cells, in pseudochains $(1,11)$. It will be interesting to examine pseudochain formation by foreign isolates of $O$. neolycopersici $i$ and to study the effect of other factors (wetting or drying of the fungus or host, irradiance, and air temperature) affecting the release of mature conidia (2). Our principle interest is to identify the factors that determine the number of conidial cells in the pseudochains of the tomato powdery mildew fungus.

The pseudochain conidial cells separated with the micromanipulator germinated normally. Our preliminary examination revealed that the conidia of pseudochains form primary haustoria in the epidermal cells when transferred to tomato leaves (data not shown). These results suggest that pseudochain conidial cells were mature and infectious. Nevertheless, some external forces are still necessary for their successful discharge into the air. Spores of many fungal pathogens (Puccinia spp., Uromyces phaseoli, Ustilago spp., Erysiphe spp., and Drechslera spp.) are liberated passively from the host by wind, although other pathogens actively release their spores independent of wind forces (2). Obviously, KTP-01 requires the wind to disperse mature conidia from conidiophores. In fact, insufficient or weak wind resulted in the failure of conidia to release from the conidiophores or the colony. 
Although the present data do not necessarily rule out the involvement of high humidity in the formation of pseudochains by other isolates of the pathogen, we should not suppose that high humidity is the sole triggering factor for conidial pseudochain formation in this pathogen. Actually, our observations show that high $\mathrm{RH}$ did not result in the formation of pseudochains by the isolates collected from various areas of Japan. For field workers, it is of practical importance to check the wind strength surrounding tomato plants, especially in the greenhouse. In our preliminary measurements, wind of $1.0 \mathrm{~m} / \mathrm{s}$ was strong enough to disperse mature conidia from conidiophores, irrespective of the given RH. Under weak wind conditions, we often observed different conidiophore types in the same colonies, because the cycle of pseudochain formation by these conidiophores is asynchronous.

In the present field assay, we demonstrated the relationship between wind strength and pseudochain formation by $O$. neolycopersici. Observation of powdery mildew colonies of field tomato at two different times (a day after a strong wind versus 5 days after calm weather) clarified this relationship. Calm weather permitted conidiophores to produce numerous pseudochains, whereas a stronger wind blew off the conidia (and pseudochains) to produce new single conidial cells at their apex. Under controlled laboratory conditions, we confirmed the possible dispersal of pseudochains from the leaves of greenhouse-inoculated and field-infected tomato plants.

The stronger wind dispersed conidia in pseudochains from the leaf surface as well as from the conidiophore apex. These conidial cells remained in single form and no pairs or pseudochains formed. These results suggest that the pseudochain conidial cells can be dispersed singly by a sufficiently strong wind. A germination rate of $72.5 \%$ was obtained from fresh conidia and those that had been deposited on the leaf surface. This was interesting because the older conidia deposited on the leaf surface apparently had good germination rates. Preliminary observations show that conidia in pseudochains that land at the base of the colony do not germinate, but do so when transferred to fresh leaves. We conclude that $O$. neolycopersici continuously develops conidia at the conidiophore apex and conidia in pseudochains are wind dispersed during strong wind conditions. When wind strength is insufficient to cause dispersal of single cells, pseudochains form and drop to the leaf surface where they are available for subsequent dispersal.

\section{LITERATURE CITED}

1. Arredondo, C. R., Davis, R. M., Rizzo, D. M., and Stahmer, R. 1996. First report of powdery mildew of tomato in California caused by an Oidium sp. Plant Dis. 80:1303.

2. Aylor, D. E. 1990. The role of intermittent wind in the dispersal of fungal pathogens. Annu. Rev. Phytopathol. 28:73-92.

3. Bélanger, R. R., and Jarvis, W. R. 1994. Occurrence of powdery mildew (Erysiphe sp.) on greenhouse tomatoes in Canada. Plant Dis. 78:640.

4. Burgerjon, A., Nicot, P. C., Bertrand, F., and Blancard, D. 1990. Early powdery mildew of greenhouse-grown tomatoes in France. (Abstr.) Phytopathology 80:1063.

5. Fletcher, J. T., Smewin, B. J., and Cook, R. T. A. 1988. Tomato powdery mildew. Plant Pathol. 37:594-598.

6. Jones, H., Whipps, J. M., and Gurr, S. J. 2001. The tomato powdery mildew fungus Oidium neolycopersici. Mol. Plant Pathol. 2:303-309.

7. Jones, H. E., Whipps, J. M., Thomas, B. J., Carver, T. L. W., and Gurr, S. J. 2000. Initial events in the colonisation of tomatoes by Oidium lycopersici, a distinct powdery mildew fungus of Lycopersicon species. Can. J. Bot. 78:1361-1366.

8. Karasevicz, D. M., and Zitter, T. A. 1996. Powdery mildew occurrence on greenhouse tomato plants in New York. Plant Dis. 80:709.

9. Kashimoto, K., Matsuda, Y., Matsutani, K., Sameshima, T., Kakutani, K., Nonomura, T., Okada, K., Kusakari, S., Nakata, K., Takamatsu, S., and Toyoda, H. 2003. Morphological and molecular characterization for a Japanese isolate of tomato powdery mildew Oidium neolycopersici and its host range. J. Gen. Plant Pathol. 69:176-185.

10. Kiss, L. 1996. Occurrence of a new powdery mildew fungus (Erysiphe sp.) on tomatoes in Hungary. Plant Dis. 80:224.

11. Kiss, L., Cook, R. T. A., Saenz, G. S., Cunnington, J. H., Takamatsu, S., Pascoe, I., Bardin, M., Nicot, P. C., Sato, Y., and Rossman, A. Y. 2001. Identification of two powdery mildew fungi, Oidium neolycopersici sp. nov. and $O$. lycopersici, infecting tomato in different parts of the world. Mycol. Res. 105:684-697.

12. Kiss, L., Takamatsu, S., and Cunnington, J. H. 2005. Molecular identification of Oidium neolycopersici as the causal agent of the recent tomato powdery mildew epidemics in North
America. Plant Dis. 89:491-496.

13. Matsuda, Y., Kashimoto, K., Takikawa, Y., Aikami, R., Nonomura, T., and Toyoda, H. 2001. Occurrence of new powdery mildew on greenhouse tomato cultivars. J. Gen. Plant Pathol. 67:294-298.

14. Matsuda, Y., Mori, Y., Sakano, Y., Nishida, M Tarumoto, K., Nonomura, T., Nishimura, H. Kusakari, S., and Toyoda, H. 2005. Screening of wild Lycopersicon species for resistance to Japanese isolate of tomato powdery mildew Oidium neolycopersici. Breed. Sci. 55:355360.

15. Matsuda, Y., Sameshima, T., Moriura, N., Inoue, K., Nonomura, T., Kakutani, K., Nishimura, H., Kusakari, S., Takamatsu, S., and Toyoda, H. 2005. Identification of individual powdery mildew fungi infecting leaves and direct detection of gene expression by single conidium PCR. Phytopathology 95:11371143.

16. Moriura, N., Matsuda, Y., Oichi, W., Nakashima, S., Hirai, T., Sameshima, T., Nonomura, T., Kakutani, K., Kusakari, S., Higashi, K., and Toyoda, H. Consecutive monitoring of lifelong production of conidia by individual conidiophores of Blumeria graminis f. sp. hordei on barley leaves by digital microscopic techniques with electrostatic micromanipulation. Mycol. Res. 110:18-27.

17. Neshev, G. 1993. Powdery mildew (Oidium sp.) on tomatoes in Bulgaria. Phytoparasitica 21:339-343.

18. Noordeloos, M. E., and Loerakker, W. M. 1989. Studies in plant pathogenic fungi-II. On some powdery mildews (Erysiphales) recently recorded from the Netherlands. Persoonia 14:51-60.

19. Oichi, W., Matsuda, Y., Sameshima, T., Nonomura, T., Kakutani, K., Nishimura, H., Kusakari, S., and Toyoda, H. 2004. Consecutive monitoring for conidiogenesis by Oidium neolycopersici on tomato leaves with a highfidelity digital microscope. J. Gen. Plant Pathol. 70:329-332.

20. Olalla, L., and Torés, J. A. 1998. First report of powdery mildew of tomato caused by an Erysiphe sp. in Spain. Plant Dis. 82:592.

21. Pernezny, K., and Sonoda, R. M. 1998. Powdery mildew of field-grown tomato in Florida Plant Dis. 82:262

22. Smith, V. L., Douglas, S. M., and LaMondia, J. A. 1997. First report of powdery mildew of tomato caused by an Erysiphe sp. in Connecticut. Plant Dis. 81:229.

23. Vakalounakis, D. J., and Papadakis, A. 1992. Occurrence of a new powdery mildew of greenhouse tomato in Greece, caused by Ery siphe sp. Plant Pathol. 41:372-373.

24. Whipps, J. M., Budge, S. P., and Fenlon, J. S. 1998. Characteristics and host range of tomato powdery mildew. Plant Pathol. 47:36-48.

25. White, J. F., Jr., Johnston, S. A., Wang, C.-L., and Chin, C.-K. 1997. First report of powdery mildew in greenhouse-grown tomatoes in New Jersey. Plant Dis. 81:227. 